
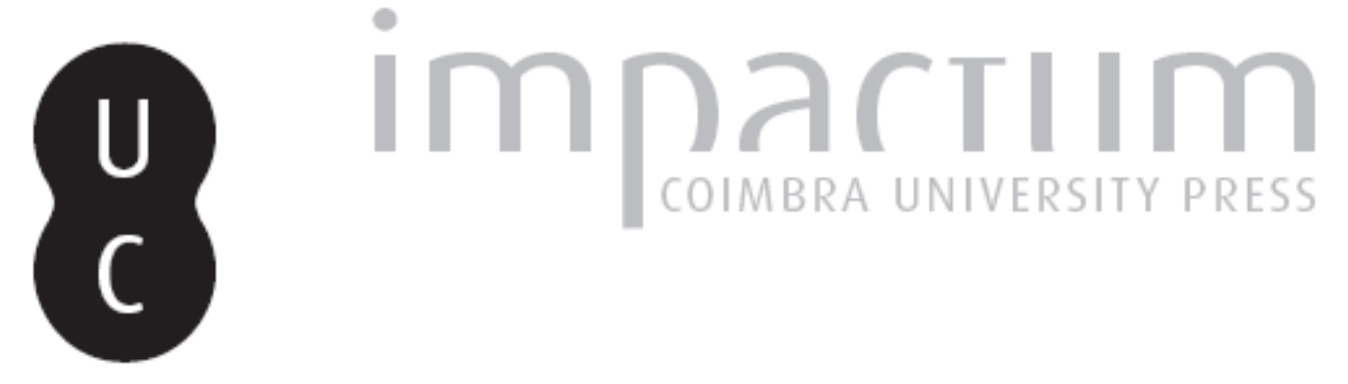

\title{
A interpretação heideggeriana de Aristóteles
}

\section{Autor(es): Blanc, Mafalda}

Publicado por: Faculdade de Letras da Universidade de Coimbra, Instituto de Estudos \section{Filosóficos}

URL persistente:

DOI: $\quad$ DOI:http://dx.doi.org/10.14195/0872-0851_47_5

Accessed : $\quad$ 26-Apr-2023 15:15:26

A navegação consulta e descarregamento dos títulos inseridos nas Bibliotecas Digitais UC Digitalis, UC Pombalina e UC Impactum, pressupõem a aceitação plena e sem reservas dos Termos e Condições de Uso destas Bibliotecas Digitais, disponíveis em https://digitalis.uc.pt/pt-pt/termos.

Conforme exposto nos referidos Termos e Condições de Uso, o descarregamento de títulos de acesso restrito requer uma licença válida de autorização devendo o utilizador aceder ao(s) documento(s) a partir de um endereço de IP da instituição detentora da supramencionada licença.

Ao utilizador é apenas permitido o descarregamento para uso pessoal, pelo que o emprego do(s) título(s) descarregado(s) para outro fim, designadamente comercial, carece de autorização do respetivo autor ou editor da obra.

Na medida em que todas as obras da UC Digitalis se encontram protegidas pelo Código do Direito de Autor e Direitos Conexos e demais legislação aplicável, toda a cópia, parcial ou total, deste documento, nos casos em que é legalmente admitida, deverá conter ou fazer-se acompanhar por este aviso.

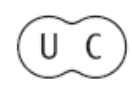




\section{REVISTA FILOSÓFICA COIMBRA}

vol. 24 - número 47- março 2015

vol. 24 - número 47- março 2015

Fundação Eng. António de Almeida

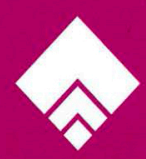




\title{
A INTERPRETAÇÃO HEIDEGGERIANA DE ARISTÓTELES
}

\author{
MAFALDA BLANC
}

Resumo: No entender de Heidegger, em Aristóteles confluem duas determinações reitoras da filosofia grega anterior, o logos e a physis, que ele assimila e transmite à posteridade, não sem as alterar significativamente. Assim, seguindo Platão no que concerne a interpretação predicativa do ser, o Estagirita toma o enunciado como fio condutor da análise ontológica, considerando as categorias e, desde logo a substância, as determinações essenciais do ser. Ao mesmo tempo, porém, que assim entronizava a lógica como fundamento da metafísica, Aristóteles foi também o pensador do movimento. Na sua Física ainda ecoa a memória da visão pré-socrática da natureza como eclosão, vinda à presença do presente. Na acção, entendida a partir da correlação entre a potência e o acto como o pôr-se em obra da verdade, reside, para Heidegger, a significação reitora do ser em Aristóteles. Ele acabou, no entanto, por reduzi-la à significação categorial, porquanto não dispunha de um conceito de tempo adequado à sua intuição do ser como possibilidade.

Palavras-Chave: ser, ente, substância, categoria, proposição, teoria, vida fáctica, acção, movimento, acto, potência e temporalidade.

\begin{abstract}
In Heidegger's view, in Aristotle converge two main determinations of precedent greek philosophy, logos and physis, that he assumes and transmits to posterity not without significant modifications. So, following Plato in being's predicative interpretation, the Stagira's takes proposition as the conducting wire of ontological analysis, taking categories, mainly substance as being's essential determinations. At the same time, however, he enthrones logic as metaphysic's ground, Aristotle was also the thinker of movement. In his book of Physics still echoes the memory of presocratic's vision of nature as appearance, presentification of presence. In action, view from the correlation between potency and act as the putting in work of truth, lies, for Heidegger, the leading meaning of being in Aristotle. But he finished to

* Professora no Departamento de Filosofia na Faculdade de Letras da Universidade de Lisboa; mafaldablanc@hotmail.com
\end{abstract}


reduce it to categorical meaning, because he doesn't had a concept of time appropriate to his being's intuition as possibility.

Keywords: being, substance, category, proposition, theorie, factic life, action, movement, act, potency.

\section{O diálogo de Heidegger com Aristóteles: contexto interpretativo}

É bem conhecido que Heidegger não dissociava o trabalho filosófico da investigação histórico-crítica da Tradição, a qual representava para ele um mediador indispensável ao mesmo tempo que um obstáculo ao genuíno entendimento das questões. É que o "ser-aí"(Dasein), sendo temporal e histórico na sua essência, é-o também na sua maneira de questionar, quer no que concerne pressupostos, quer pontos de vista ou perspectivas de interpretação. Consagrou, por isso, grande parte da sua obra ao diálogo com as grandes figuras da história da filosofia, considerando-o uma componente indispensável do filosofar pela abertura de vias e problemáticas que promove.

Todavia, nessa "desmontagem"(Destruktion) da Tradição, pois é disso que se trata, o filósofo deu um lugar de destaque a Aristóteles, pois este representava para ele o ponto de viragem de uma interpretação inicial do ser como eclosão para o essencialismo, em que passaria a vigorar uma abordagem já categorial e lógica do ser. Nos cinco anos que precedem a publicação de "Ser e Tempo", em 1927, Heidegger dedicou ao Estagirita grande parte dos seus cursos, regressando a ele mais tarde em dois textos fundamentais consagrados à análise do movimento e à significação do ser como dynamis e energeia. ${ }^{1}$ São eles o curso sobre o conceito de "força"(Kraft) em Aristóteles, de 1931, dedicado à interpretação dos primeiros capítulos do livro nono da "Metafísica" e, alguns anos mais tarde, em 1939, o Seminário sobre o conceito de physis em Aristóteles, a partir do comentário ao segundo livro da "Física". ${ }^{2}$ Em ambos, o que está em causa já não é mostrar como é que o "ser-aí"(Dasein) perfaz, pela sua existenciaridade, o seu dizer apofântico, o lugar originário do desvelamento do ser, mas antes que a compreensão do ser é regida pelo fenómeno da mobilidade, da vinda ao presente da presença,

1 De 1922 a 1927, Heidegger consagra vários cursos a Aristóteles, que as "Obras completas"(Gesamtausgabe, que, doravante, abreviaremos pela sigla GA, seguida do número do respectivo tomo) tornaram disponível: GA 62(1922); GA 18(1924); GA 33(1931). Outros cursos dão um grande lugar ao pensamento e aos textos de Aristóteles: GA 61(19211922); GA 17(1923-24); GA 19(1924-25); GA 21(1925-26); GA 22(1926) e GA 24(1927).

2 Conf. M. Heidegger, Aristoteles, Metaphysik IX 1-3. Von Wesen und Wirklichkeit der Kraft, GA 33 (Frankfurt am Main: V. Klostermann, 1990) e "Vom Wesen und Begriff der Fúsis. Aristoteles, Physik B, 1"in Wegmarken, GA 9, 1996. 
onde vige o próprio tempo. A intenção é relevar como o próprio Aristóteles desenvolve, em paralelo à interpretação ousiológica do ser como presença, uma distinta e mais fundamental compreensão deste orientada para o que funda toda a temporalidade, a saber, a dynamis, interpretada como força, ponto de partida para uma mudança.

O interesse de Heidegger por Aristóteles, porém, remonta bem longe, aos tempos da sua juventude, e prende-se com uma dupla preocupação: a primeira, de ordem teológica, concerne a discussão do filósofo com a teologia católica da época, dominada pela escolástica e uma interpretação da experiência cristã esvaziada de conteúdo; a segunda, de ordem propriamente filosófica mas com aquela relacionada, diz respeito à questão da significação múltipla do ser, que Heidegger herdara de Aristóteles através da leitura de Brentano. ${ }^{3}$

No que diz respeito à primeira, há que atender a que Heidegger, de formação católica, tinha sido iniciado à filosofia pela teologia escolástica, que pôde conhecer e dominar em toda a sua profundidade nos anos de Seminário e, depois, na Universidade. Mais tarde, já entregue à filosofia, viria a sentir-se insatisfeito com a sua rigidez e imobilismo e a aproximar-se de posições evangélicas, lendo autores como Lutero, Kierkegaard ou Barth que, ao contrário, relevam a historicidade da fé. Nos dez anos que precederam a obra magna, Heidegger anda à procura de um ponto de vista a partir do qual the seja possível dar um novo arranque à questão do ser, então incompreendida e esvaziada de sentido. Sob o influxo de Dilthey, descobre a centralidade da "vida fáctica"(faktische Leben) ou histórica do homem para a questão do ser e procura as bases filosóficas para uma interpretação antropológica adequada de fenómenos relevados pela consciência cristã primitiva, tais como a inquietude da vida, o cuidado e o carácter insigne do instante, em que se decide a resposta ao apelo do kerigma. ${ }^{4}$ A seu ver, o que faltou à teologia católica para vencer a tentação do dogmatismo foi justamente uma hermenêutica adequada da facticidade. Para o entender, porém, importa desconstruir a tradição, regressar às fontes originais que inspiraram a escolástica tardia e a impediram de realizar uma explicitação adequada da experiência da fé. Apesar de relevar a importância de Santo Agostinho e do Neo-platonismo, a atenção de Heidegger vai sobretudo para Aristóteles, pois foi nele que se baseou a teologia medieval para edificar a onto-teologia, ou seja, uma sistemática do ser fundada numa concepção eternalista do Divino, entendido como esse Ente primeiro, que se mantem no presente de uma efectuação contínua.

3 Conf. a dissertação de Brentano, Von der mannigfachen Bedeutung des Seienden nach Aristoteles (1862)/De la Diversité des Acceptions de l'Être d'après Aristote, trad. franc. de P. David ( Paris: Vrin, 1992) e o testemunho biográfico de Heidegger em Mein Weg in die Phänomenologie, in GA 14, 93 ou, ainda, na célebre Brief an Richardson (1962,) in GA 11, 145-146.

4 Veja-se Heidegger, Phänomenologie des religiösen Lebens (1920-21),GA 60, 1995. 
Sem ser falsa, a leitura escolástica do Estagirita acabaria por impossibilitar uma outra, a ver de Heidegger também possível, em torno da ideia de vida fáctica e da sua auto-explicitação, onde ressalta por contraste o fenómeno da mudança e da realização existencial. É ela que Heidegger pretende levar a cabo nas suas interpretações fenomenológicas de Aristóteles, como o próprio afirma no "Manuscrito-Natorp"- um relatório programático sobre o estado das suas investigações de Aristóteles, redigido em 1922 a pedido daquele último filósofo para uma eventual candidatura à docência em Marburgo. ${ }^{5}$ O nosso filósofo propõe-se ali abordar o texto no original libertando-o da indumentária escolástica e latina, restituir a palavra ao autor, evidenciando, subjacente a toda a conceptualização, o carácter fenomenológico e concreto do modo de pensar do Estagirita.

A segunda motivação que leva Heidegger a um continuado diálogo com Aristóteles é, como adiantámos atrás, de índole mais propriamente filosófica. Ela concerne a questão do ser, a sua formulação, onde o filósofo reconhece algo das suas próprias preocupações. É que, apesar do Estagirita centrar no ente aquela que é, para Heidegger, a questão da filosofia - pois a pergunta "a partir de onde o ente é realmente ente?", subtrai o aberto da eclosão do ser próprio do pensamento anterior -, o Estagirita não deixaria de relevar a diversidade das acepções do ser, o que é para Heidegger uma conquista essencial da Ontologia. ${ }^{6}$ Pois foi esse, com efeito, o seu ponto de partida em filosofia, com o qual, ainda jovem, fora alertado por Brentano para a relevância da questão do ser. Assim, se o ser-ente, de acordo com Aristóteles, aparece/ /diz-se de múltiplos modos - a acepção categorial, a veritativa, a potência e o acto, e o ser "por si próprio" (kath'autó), por oposição ao modo acidental cabe então perguntar qual a relação que eles têm entre si, qual a significação reitora a partir da qual o ente é o que é? E o mesmo será inquirir: que significa afinal ser, como se determina a sua essência? ${ }^{7}$

Excluídas as acepções veritativa e acidental, o Estagirita oscila entre a acepção categorial e modal, acabando por privilegiar a primeira, como parece indicar entre outros o livro VII da "Metafísica". E isso porque nas três abordagens que refere do homem à realidade - a techné, a theoria e a praxis -, deu primazia às primeiras, em detrimento desta última. Heidegger, pelo contrário, inverte as prioridades, valorizando o plano da acção, da reali-

5 Conf. Heidegger, Interprétations phénoménologiques d'Aristote, trad. franc. De J. F. Courtine, (Manvezin: Trans-Europ-Repress, 1992). Veja-se ainda os dois primeiros cursos sobre Aristóteles, de 1921 e 1922, Phänomenologische Interpretationen zu Aristoteles, GA, 61 e Phänomenologische Interpretation ausgewälter Abhandlung des Aristoteles zu Ontologie und Logik, GA, 62.

6 Conf. Aristóteles, Metaph. IV 1 e 2; VI 2; VII 1.

7 Veja-se Op. Supra-citada, V 7 e Heidegger, Brief an Richardson, GA 11, 145-146. 
zação existencial. É que, em seu entender, a consideração teorética do ente a partir de princípios que determinam a sua forma e constância, na sua postura abstractiva, vela o processo de desocultação e realização do ser, por que toda a presença se desdobra e se retoma; deixa assim o campo livre para a investigação do ente na sua "natureza" e causas, que outros mais tarde, à procura de uma sistemática do ser, iriam promover, abrindo caminho ao esvaziamento do seu sentido. Heidegger quer mostrar como é possível uma outra abordagem do texto aristotélico, antes focalizada na questão da acção e do movimento, evidenciando na Ética Nicomaqueia o esboço de uma fenomenologia do modo de ser do vivente com logos, que já anuncia as bases dessa antropologia filosófica que considera indispensável a uma nova Ontologia. ${ }^{8}$ É que, a seu ver, o ponto de vista da práxis revela, melhor do que o teorético, o processo de realização do possível, por que se pauta a experiência do viver na sua ineludível matriz temporal e histórica.

\section{O logos como fio condutor da análise ontológica e o primado da presença}

A originalidade da leitura heideggeriana de Aristóteles reside no seu carácter fenomenológico. Significa isto que aplicou ao texto grego o que a fenomenologia dos actos da consciência vinha dizendo acerca do manifestar-se do fenómeno, do seu aparecer a uma consciência numa correlação intencional de noese e de noema. ${ }^{9}$ Mas ao fazê-lo, descobriu também que o Estagirita, pelo seu modo grego de pensar, mais atinente às "coisas mesmas"(Sache selbst) do que à auto-certificação da consciência, pensou o fenómeno mais originalmente do que Husserl como o aparecer do próprio ser tal como ele, de si e em múltiplos modos, vem à presença. ${ }^{10} \mathrm{O}$ termo "fenomeno-logia",

8 O primeiro anúncio da hermenêutica da facticidade é feito por Heidegger em 1923 num curso de Friburgo com aquela designação, imediatamente após os primeiros cursos sobre Aristóteles. Conf. Heidegger, Ontologie. Hermeneutik der Faktizität, GA, 63.

9 Conf. Heidegger, Brief an Richardson, GA 11, 146-147 e Mein Weg in die Phänom., GA 14, 97, onde afirma:'Indes konnte ich mich von Aristoteles und den anderen griechischen Denkern um so weniger trennen, je deutlicher mir die wachsende Vertrautheit mit dem phänomenologischen Sehen die Auslegung der Aristotelischen Schriften befruchtete.'[Entretanto, menos eu podia separar-me de Aristóteles e dos outros pensadores gregos, mais se tornava evidente o fruto que eu retirava para a interpretação de Aristóteles da minha familiaridade crescente com o olhar fenomenológico.]

10 Conf. Ibid, 99:"Was sich für die Phänomenologie der Bewusstseinsakte als das sichselbst-Bekunden der Phänomene vollzieht, wird ursprünglicher noch von Aristoteles und im ganzen griechischen Denken und Dasein als Alétheia gedacht, als die Unverborgenheit des Anwesenden, dessen Entbergung, sein sich-Zeigen."[O que para a fenomenologia dos 
entendido à maneira helénica, significa, com efeito, para Heidegger, a insigne correlação entre o que se manifesta e o mostrar, o dizer que a alma humana efectua enquanto descobridora, quer dizer, reportada numa relação intencional a conteúdos inteligíveis e, desde logo, ao próprio ser. ${ }^{11}$

No De Anima delineou Aristóteles os princípios de uma descrição do existente humano na sua abertura ao ser. Considera aí que, apesar de o homem ter, como qualquer outro vivente, um princípio de animação corporal, a alma, a partir do qual e no qual a vida se desdobra e mantem como relação, tensão para algo e desejo, ele não está, contudo, como o animal, condicionado pelo objecto, antes se abre ao seu carácter de ente e com ele entra numa livre relação. ${ }^{12}$ Longe, pois, de ficar encerrado como aquele no círculo repetitivo da pulsão, habita o aberto de um mundo, descobre-o e deixa-o vir ao encontro já desde o nível da percepção, nele se dispondo e movendo segundo uma linha de orientação. E isso de modo tanto mais indeterminado que o seu viver, que é um agir acompanhado de logos, ou seja, determinado pela estrutura significativa do "enquanto" (Als-Struktur), é o lugar de uma abertura de possibilidades contrárias entre as quais tem de escolher numa síntese sempre a reefectuar no contexto mutável do viver e no momento oportuno. ${ }^{13}$

Assim, se oagir, com saber práticoqueoilumina-a“prudência"(phronêsis), parece constituir o lugar originário da emergência do sentido, da abertura ao mundo e a si do existente humano, ele não perfaz certamente para o Estagirita, observa Heidegger, nem a única nem a principal forma de descobrimento da realidade. ${ }^{14}$ Ultrapassam-no em importância quer a technê, o fazer produtivo, quer a sophia, a sabedoria, pela capacidade que ambos têm de apreender conteúdos estáveis, o eidos ou os "princípios"(archai), sempre

actos da consciência se cumpre como o manifestar-se do fenómeno, é pensado mais originalmente ainda por Aristóteles e em todo o pensamento e existência gregos como Alétheia, como o aberto sem retiro do que se presentifica, o seu desvelamento, o seu mostrar-se.]

11 Heidegger,Sein und Zeit, GA 2, § 7, c), 46:”Der Ausdruck Phänomenologie lässt sich griechisch formulieren: legein ta phainomena; legein besagt aber apophainestai. Phänomenologie sagt dann: apophainestai ta phainomena: Das was sich zeigt, so wie es sich von ihm selbst her zeigt, von ihm selbst her sehen lassen."'A expressão fenomenologia deixa-se formular de modo grego: legein ta phainomena; legein significa então: apophainestai ta phainomena:o que se mostra, tal como de si próprio se mostra, fazê-lo ver a partir de si mesmo.]

12 Veja-se Aristóteles, De Anima, III 9 e segs.

13 Veja-se Aristóteles, Metaph., IX, 2 e o comentário de Heidegger no já por nós citado curso Aristoteles, Metaphysik IX 1-3, GA 33, 2ª secç., §§ 13-14, 117 e segs.

14 Veja-se a análise da phronêsis a partir do comentário a Étic. a Nic., VI 5, e do primado da sophia em Heidegger, Platon: Sophistes (1924/25), GA 19, §§ 8 e 9, 48-56 e, ainda, $\S \S 18-25,132-178$; conf. ainda, sobre a superioridade da sophia, o já citado "Manuscrito-Natorp"in Heidegger, Interprétations phénoménologiques d'Aristote, 37 e segs. 
disponíveis no presente da intuição. ${ }^{15} \mathrm{E}$ como a cada orientação para a realidade corresponde um modo distinto dela aparecer - é o quomodo e o quid do "fenómeno" no teor concreto da correlação que o constitui - os objectos da poieisis e da sophia terão de ser distintos daquele outro da praxis. Já não o âmbito sempre variável do possível que o discurso interpretativo articula numa síntese concreta de nome e verbo, mas o plano do efectivo, da objectividade mundana, acessível no presente da ocupação ou da consideração intelectual, e depois articulável na proposição. ${ }^{16}$

Porque ficou preso do privilégio ontológico concedido ao presente da presentificação, sempre ao dispor da objectivação teorética, Aristóteles foi levado a considerar a predicação como o lugar da articulação da verdade, reduzindo de algum modo o "ser" à função de cópula de ligação entre o sujeito e predicado. Iniciou assim o domínio da lógica sobre o pensar e o seu modo de entender a realidade, contaminando pela gramática o nosso modo de falar do ser, de elidir o seu sentido temporal. É que na passagem do logos hermenêutico para o apofântico, a estrutura explicitativa do "enquanto" sofre uma significativa modificação: perde a conotação temporal de presente no seu estado nascente, actualizando uma possibilidade, para ganhar aquela outra de estado de coisas aí diante no agora de uma efectividade. ${ }^{17}$ De modo que, em vez de atender ao aberto do ser que, tudo diferenciando e recolhendo, se exprime através de todas as línguas, e de, assim, constituir a resposta

15 Heidegger, GA 19, §§ 6 e 7, 31-47.

16 Sobre a objectividade mundana, referência maior da ontologia natural dos Gregos, veja-se, entre outros, Ibid, § 42, b), 269-271 e Heidegger, Grundbegriffe der antiken Philosophie(1926), GA 22, anexo ad. 86, onde se pode ler em 313:"Die giechische Ontologie ist eine Ontologie der Welt. Das Sein wird interpretiert als Anwesenheit und Beständigkeit."[ A Ontologia grega é uma Ontologia do mundo. O ser é interpretado enquanto presença e subsistência.] Veja-se ainda, sobre o sentido do ser em Aristóteles, Heidegger, Interprétations phénoménologiques d'Aristote,34-35, onde se pode ler:'Was besagt überhaupt Sein für Aristoteles (...)? (...) Nicht das Seinsfeld der Dinge als einer theoretisch sachhaft erfassten Gegenstandsart, sondern die begegnende Welt im herstellenden, verrichtenden und gebrauchenden Umgang (...). Sein besagt Hergestelltsein,(...), Verfügbarsein.”[O que significa em geral ser para Aristóteles (...)? (...) Não o domínio ontológico das coisas enquanto objectos específicos apreendidos teoreticamente no seu teor real, mas o mundo tal como ele se encontra no comércio da produção, da execução, do uso (...). Ser significa ser produzido (...), estar disponível.]

17 Sobre o logos hermenêutico e apofântico, veja-se, Heidegger, Platon:Sophistes, $\S 26, \mathrm{~b}), 181, \S 80,581-606$ e Sein und Zeit, $\S \S 32-33$, em especial p. 211, onde afirma:"'Das ursprüngliche "Als" der umsichtig verstehenden Auslegung (hermeneia) nennen wir das existenzial-hermeneutische "Als" im Unterschied vom apophantischen "Als" der Aussage."[ O "enquanto que" original, o da interpretação compreensiva por discernimento (hermeneia), designamos nós por "enquanto que" hermenêutico-existenciário para o distinguir do "enquanto que"apofântico do enunciado.] 
pensante que o homem dá ao que se manifesta - a articulação significativa do conjunto de relações que estruturam um mundo e determinam o aparecer dos entes intramundanos -, a palavra pensante da filosofia tornou-se, com o privilégio dado à predicação, a expressão das condições que o pensar estatui para o ser verdadeiro. ${ }^{18}$

No enunciado é dito algo acerca de algo e vem à linguagem o "é", o Ser. Por isso, se se deve decidir sobre este - e tal é, para o Estagirita, o propósito da "filosofia primeira" (protê philosophia) -, o enunciado deve ser interrogado. Os vários modos do ser são recolhidos nos vários modos do "predicar" (katégorein) acerca de algo, de considerar as coisas enquanto elas são isto ou aquilo. As categorias tornam-se as determinações formais mais gerais do ser e a Ontologia uma teoria das categorias. ${ }^{19}$ Elas reportam-se ao que está aí diante, ao que se apreende na imediatez da aisthesis, da natureza e do espacial - o ente efectivado, o" indivíduo" (tode ti), que é o termo de um movimento de produção, natural ou artificial. Mas o que se assim se presentifica e está na base de um ver e de um dizer objectivantes, tem a sua presença em e através do aspecto, da "ideia". Ele é o que a cada momento se apresenta sob uma certa forma e tem a sua constância e permanência na ousía, o ser “por si"(kath'autó), que, estando já sempre aí no presente de uma efectuação, permite uma apreensão constante e certa do real. Mais tarde traduzida por essentia e substantia, a ousía, que Heidegger aproxima ou mesmo lê como parousia, torna-se a primeira das determinações do ser, a que se reportam as demais categorias. ${ }^{20}$ É ela que legitima que a Ontologia venha a compreender-se como uma ousiologia.

\section{A mobilidade, significação reitora do ser e a elisão do tempo}

Excluídas as acepções acidental e veritativa do ser, reportadas as categorias à ousía, resta então explicitar qual a relação desta com a acepção modal do ser. Contrariamente a Brentano, que interpretava a dynamis no sentido lógico-categorial da possibilidade, reduzindo-a à identidade formal da essência, Heidegger quer relevar o seu sentido ontológico-existenciário juntamente com a sua primazia. Para isso remonta à Física, que é, a seu ver,

18 Conf. Heidegger, Einführung in die Metaphysik, GA, 40, §§ 55-56, 187-205.

19 As categorias constituem o primeiro grupo das quatro acepções do ser, como atrás referimos. Veja-se, a seu respeito, os comentários de Heidegger no curso Grundbegriffe der antiken Philosophie, GA, 22, § 56, 156-159.

20 Conf. Aristóteles, Metaph., IV 2 e Heidegger, GA, 22, § 57, 162:”ousía: Sie drückt das ursprüngliche Sein aus, in bezug auf sie gibt es Mitvorhandenheit, Weisen."[ousía: exprime o ser originário, é relativamente a ela que há ser-aí em face com, modos.] 
o ponto de partida da análise ontológica da Metafísica e o verdadeiro centro do pensamento aristotélico. "Livro de fundo da filosofia ocidental", é ali que, a seu ver, se leva a cabo a primeira tentativa de determinar de forma pensante a essência da natureza e se procura elevar o movimento que a caracteriza à dignidade de uma determinação essencial do ser, por oposição à idealidade matemática de inspiração platónico-aristotélica. ${ }^{21}$

O movimento, na sua tripla expressão (deslocação de lugar, crescimento e diminuição e alteração), apresenta a estrutura formal de uma "passagem de isto a isto"(metabolé ek tinos eis ti), através da qual algo, até aí velado e ausente, aparece, vem à presença. ${ }^{22}$ Assemelha-se assim à "fabricação", que é, também ela, um movimento de "trazer-para-diante"(hervor-bringen), uma produção, porém não tem, como esta, fora de si o seu princípio motor, mas nele. ${ }^{23}$ A natureza é, por isso, um "princípio originante"(archê) que se põe a si mesmo em presença, um eclodir que se desdobra num regressar a si, uma génese que se retira em si e se ausenta. ${ }^{24}$ Quer isto dizer que, no seu vir a si, ela completa um ciclo vital: desabrocha e cresce estendendo-se para diante, vai a caminho da sua "compleição" (entelécheia), atinge a plenitude da sua forma completa e começa a decrescer até perecer, pois esse é o termo natural do viver e até talvez o seu acto supremo. De modo que a mudança não se acrescenta à coisa, antes perfaz um princípio interno seu de transformação e desenvolvimento, de onde emerge o seu "aspecto" (eidos), a forma,a qual revela ao mesmo tempo a matéria de que ela é feita. Assim, tudo o que é segundo a natureza não cessa de emergir para fora da latência, de tender para a plenitude do seu ser, jamais está terminado como um artefacto. E no entanto, vai ser a partir deste, da sua forma acabada - o quid objectivo enunciável no logos, que o Estagirita vai pensar o movimento. Sob o olhar inquisidor da theoria e da maestria técnica, o resultado da eclosão toma então preponderância sobre a mesma, a aparição e o seu centro escondido, a potência, vão-se retirando e caiem no esquecimento. A substância passa a impor-se como um fundo que já é, uma actualidade que sustem o ente no seu ser e garante a apreensão certa e constante do conhecimento. Vejamos como.

21 Conf. Heidegger, "Vom Wesen und Begriff der Fúsis", GA 9, 242, onde afirma: "Die aristotelische "Physik" ist das verborgene und deshalb nie zureichend durchdachte Grund-buch der abendländischen Philosophie." [A "Física" de Aristóteles é, de modo escondido e por isso nunca suficientemente pensado, o livro de fundo da filosofia occidental.]

22 Conf. Arist. Física V 1, 224 b 35-225 b 9 e o comentário de Heidegger in $O p$. Supra-citada, p. 248, a que nos estamos a reportar, e, mais adiante, p. 249.

23 Heidegger, Op. Supra-cit., GA 9, 247-253.

24 Ibidem, 254:"Das sich entfaltende Aufgehen ist an sich ein In-sich-zurückgehen; diese Art der Wesung ist fúsis."[O eclodir que se desdobra é, quanto a si, um regressar-a-si; este modo da essenciação é a physis.] 
Nos primeiros capítulos do livro nono da Metafisica, Aristóteles estende a todo o tipo de actividade (anímica, técnica, política, ou mesmo divina) a sua análise do movimento físico e explicita a sua estrutura categorial. Considera aí a "potência"(dynamis) como um princípio de mudança "num outro ser ou no mesmo enquanto outro", uma capacidade de empreender algo e de o levar a bom termo que sempre regressa a si como aptidão, válida para todo o móvel e tudo o que está em repouso, para o que está sendo e o que está terminado. ${ }^{25}$ Heidegger interpreta-a como "força"(Kraft), um princípio activo de existência e de vida capaz de actualizar as possibilidades que traz em si; compreende-a como uma vontade de realização, um esforço de aperfeiçoamento orientado para um "fim"(telos), que implica um "como"(wie), um modo de implementação. Ontologicamente, ela supõe uma separação e diferença de si a si, uma relação de inclusão mútua de um "agir"(poiein) e de um "sofrer"(pathein), orientada para uma auto-superação. ${ }^{26}$ Uma força sem logos, adianta, é uma força cega, unidireccionada; iluminada por ele, porém, abre para possibilidades contrárias entre as quais há que decidir. ${ }^{27}$

O derradeiro esforço de clarificação da essência da potência fá-lo o filósofo grego no seu confronto com os Megáricos, que negavam a realidade do possível e reduziam o ser à actualidade. $\mathrm{O}$ que está em causa é saber se, quando e como um tal poder está realmente aí, efectivamente presente. ${ }^{28}$ A tese megárica sustenta que a dynamis só se encontra onde uma força está "em acção"(energeia), produzindo e realizando uma possibilidade. A grande questão, observa Heidegger, é a de saber se Aristóteles consegue refutá-la, conferindo à potência um estatuto diferente da efectividade e distinto da mera possibilidade lógica. A realidade ontológica da potência, objecta Aristóteles, é a sua posse como aptidão e não a sua realização efectiva. $\mathrm{Na}$ base desta distinção está um mais amplo e subtil entendimento da presença, que ambos interpretam como constituindo a essência do ser. Os Megáricos privilegiam a actualidade do ergon, da obra acabada, porque não compreendem de modo suficiente a essência da energeia; não só lhes escapa a presença da realização como a da própria possibilidade. Porque não admitiam o movimento, a transição de um estado a outro, não podiam entender o que significa iniciar ou cessar uma actividade - não adquiri-la ou perdê-la, mas retomá-la como aptidão. ${ }^{29}$

25 Conf. Aristóteles, Metaph. IX 1, 1046 a 10-30.

26 Conf. Heidegger, Aristoteles, Metaphysik IX 1-3, GA 33, 67 e segs.; sobre o mesmo texto, veja-se ainda as observações do curso Die Grundbegriffe der antiken Philosophie, GA 22, § 60-64, 168 em diante.

27 Aristóteles, Metaph. IX 2, 1046 b 5 e segs. e Heidegger, GA 33, § 13, 117 e segs.

28 Conf. Arist., Metaph. IX, 3 e Heidegger, Ibidem, § 17, p. 167 e segs.

29 Heidegger, Ibid., § 21, 207 e segs. 
Na passagem da potência à entelécheia está de algum modo incluída a realização existencial da essência, que a filosofia ulterior preteriu em prol da consideração abstracta desta última, e esse foi, aos olhos de Heidegger, o grande mérito do Estagirita - o de ter pensado a "presencialidade" (Anwesenheit) do ser como um campo dinâmico, uma actividade de "presentificação"(Anwesung). ${ }^{30}$ Ela desdobra-se em três tempos, modalidades de ser-presente que têm a sua correspondência nas ekstases do tempo: a presença do possível - o ainda não futuro; a presença do real - o agora presente; e a presença do necessário - o passado que já não é. De forma que o traço fundamental da ousía, a presença, aponta, em Aristóteles, para o seu sentido temporal. Pensada a partir da "eksistenz", ela refere um ser que é transportado para fora de si mesmo, cindido de si, projectado num futuro a partir de um passado, desse modo abrindo um presente; o fundo, substrato activo da potência, é a raiz, a fonte de que se alimenta toda a eclosão e onde o ente se mantem e se firma.

Porém, Aristóteles não dispunha de um conceito de tempo adequado que lhe permitisse pensar a sua intuição da temporalidade do ser. A sua definição do tempo no livro quarto da Física como "número do movimento segundo o antes e o depois" segue a concepção corrente do mesmo como série de "agoras", privilegiando o presente em detrimento do passado e do futuro. O tempo, como aliás o movimento de que é a expressão anímica, é interpretado por ele a partir da ousía, da presença em acto, e como sua negação, como um não-ente ou um ente impuro, composto. ${ }^{31}$ Assim, conclui Heidegger, com o seu conceito de potência como princípio do movimento, Aristóteles foi fiel à grande intuição pré-socrática do ser como physis, a qual significava eclosão, vinda à presença do presente. Todavia, acabou por secundarizá-la, considerando-a um género de ser subordinado à entelécheia, a presença da obra acabada, o ente imóvel, que permanece e dura na sua forma constante e se dá a conhecer numa intuição adequada. A acção de ser, do tornar-se, fica assim reduzida à "entidade"(Seiendenheit) imóvel e substante do ente verdadeiro, conforme reza a doutrina do último capítulo do livro nono, verdadeiro cume da metafísica aristotélica e do pensamento antigo. ${ }^{32}$

30 Ibid., § 19, 182 e segs.

31 Veja-se, a propósito da interpretação heideggeriana do conceito aristotélico de tempo, o bem conhecido artigo de J. Derrida, "Ousía et Grammé, note sur une note de Sein und Zeit", in Derrida, Marges de la Philosophie (Paris: ed. de Minuit,1972), 31-78.

32 Veja-se o comentário de Heidegger a Aristóteles, Metaph. IX 10 no curso Von Wesen der Menschlichen Freiheit, GA 31, § 9, e), 106-108. 


\section{Referências Bibliográficas}

Brentano, F., Von der mannigfachen Bedeutung des Seienden nach Aristoteles (1862); trad. franc. De la Diversité des Acceptions de l'être d'après Aristote, Paris: Vrin, 1992.

Derrida, J., "Ousía et Grammé. Note sur une note de Sein und Zeit", in Marges de la Philosophie, Paris: ed. de Minuit, 1972.

Heidegger, M., Interprétations phénoménologiques d'Aristote, ed. bilingue, trad. franc. J.F. Courtine, Manvezin: Trans-Europ-Repress, 1992.

Heidegger, M., Gesamtausgabe (sigla GA seguida do respectivo tomo e data de edição), Frankfurt am Main: Vittorio Klostermann (trad. franc. de algumas destas obras nas éditions Gallimard, Paris): , Phänomenologie des religiösen Lebens, GA 60, 1995;

, Phänomenologische Interpretationen zu Aristoteles. Einführung in die phänomenologische Forschung, GA 61, 1985; , Phänomenologische Interpretation ausgewählter Abhandlungen des Aristoteles zu Ontologie und Logik, GA 62, 1988; , Ontologie. Hermeneutik der Faktizität, GA 63, 1988; , Platon: Sophistes, GA 19, 1992; , Grundbegriffe der antiken Philosophie, GA 22, 1993;

, Einführung in die Metaphysik, GA 40, 1983;

, Von Wesen der Menschlichen Freiheit, GA 31, 1982;

, "Brief an Richardson" in Identität und Differenz, GA 11, 1990;

, "Vom Wesen und Begriff der Fúsis. Aristoteles, Physik B, I" in Wegmarken, GA 9, 1996;

, Aristoteles, Metaphysik IX 1-3. Von Wesen und Wirklichkeit der Kraft, GA 33, 1990. 